\title{
Corto and DSPI interact and bind to a maintenance element of the Scr Hox gene: understanding the role of Enhancers of trithorax and Polycomb
}

\author{
Juliette Salvaing1,2, Martine Decoville ${ }^{3}$, Emmanuèle Mouchel-Vielh ${ }^{1}$, \\ Marianne Bussière ${ }^{1}$, Anne Daulny ${ }^{3,4}$, Lidiya Boldyreva ${ }^{5}$, Igor Zhimulev ${ }^{5}$, \\ Daniel Locker ${ }^{3}$ and Frédérique Peronnet*1
}

\begin{abstract}
Address: ${ }^{1}$ UMR 7622, CNRS, Université Pierre et Marie Curie, 9, quai Saint-Bernard, 75252 PARIS cedex 05, France, ${ }^{2}$ University Maastricht, PO Box 616, 6200 MD Maastricht, The Netherlands, ${ }^{3}$ UPR 4301, CNRS, Centre de Biophysique Moléculaire Rue Charles Sadron, 45071 Orléans cedex 2, France, ${ }^{4}$ Cold Spring Harbor Laboratory, 1 Bungtown Road, Mc Clintock Building, 11723 NY, USA and ${ }^{5}$ Institute of Cytology and Genetics, Siberian Division of Russian Academy of Sciences, Acad. Lavrentiev Avenue, 10, 630090 Novosibirsk, Russia

Email: Juliette Salvaing - j.salvaing@gen.unimaas.nl; Martine Decoville - decovil@cnrs-orleans.fr; Emmanuèle Mouchel-

Vielh - Emmanuele.Mouchel-Vielh@snv.jussieu.fr; Marianne Bussière - mariannebussiere@gmail.com; Anne Daulny - daulny@cshl.edu;

Lidiya Boldyreva - asd@bionet.nsc.ru; Igor Zhimulev - zhimulev@bionet.nsc.ru; Daniel Locker - locker@cnrs-orleans.fr;

Frédérique Peronnet* - Frederique.Peronnet@snv.jussieu.fr

* Corresponding author
\end{abstract}

Published: 14 April 2006

BMC Biology2006, 4:9 doi:10.1 186/1741-7007-4-9

This article is available from: http://www.biomedcentral.com/I741-7007/4/9

(c) 2006Salvaing et al; licensee BioMed Central Ltd.

This is an Open Access article distributed under the terms of the Creative Commons Attribution License (http://creativecommons.org/licenses/by/2.0), which permits unrestricted use, distribution, and reproduction in any medium, provided the original work is properly cited.

\begin{abstract}
Background: Polycomb-group genes (PcG) encode proteins that maintain homeotic (Hox) gene repression throughout development. Conversely, trithorax-group ( $\operatorname{tr} x G)$ genes encode positive factors required for maintenance of long term Hox gene activation. Both kinds of factors bind chromatin regions called maintenance elements (ME). Our previous work has shown that corto, which codes for a chromodomain protein, and dsp I, which codes for an HMGB protein, belong to a class of genes called the Enhancers of trithorax and Polycomb (ETP) that interact with both PcG and trxG. Moreover, $d s p /$ interacts with the Hox gene Scr, the DSPI protein is present on a Scr ME in S2 cells but not in embryos. To understand better the role of ETP, we addressed genetic and molecular interactions between corto and dspl.
\end{abstract}

Results: We show that Corto and DSPI proteins co-localize at 9 I sites on polytene chromosomes and co-immunoprecipitate in embryos. They interact directly through the DSPI HMG-boxes and the amino-part of Corto, which contains a chromodomain. In order to search for a common target, we performed a genetic interaction analysis. We observed that corto mutants suppressed dsp I' sex comb phenotypes and enhanced Antp ${ }^{S c x}$ phenotypes, suggesting that corto and $d s p /$ are simultaneously involved in the regulation of Scr. Using chromatin immunoprecipitation of the Scr ME, we found that Corto was present on this ME both in Drosophila S2 cells and in embryos, whereas DSPI was present only in S2 cells.

Conclusion: Our results reveal that the proteins Corto and DSPI are differently recruited to a Scr ME depending on whether the ME is active, as seen in S2 cells, or inactive, as in most embryonic cells. The presence of a given combination of ETPs on an ME would control the recruitment of either PcG or TrxG complexes, propagating the silenced or active state. 


\section{Background}

Many transcription factors are expressed only transiently during development. After they have disappeared, the patterns of gene expression they have induced must be inherited by daughter cells. In eukaryotes, two groups of proteins, the Polycomb-group (PcG) and the Trithoraxgroup (TrxG), fulfil this memory function. Their existence was first revealed in Drosophila melanogaster where homeotic gene (Hox) expression is established in early embryos by the transient Gap and Pair-Rule transcription factors and controlled by PcG and TrxG proteins during the rest of development [1-3]. The PcG and TrxG proteins combine into several heteromeric complexes that bind chromatin. PcG complexes maintain Hox gene silencing whereas TrxG complexes counteract the action of PcG complexes (reviewed in [4]). These proteins regulate many other genes such as engrailed [5,6], ph [7], fork head [8] and the iroquois-complex [9].

In Drosophila, at least two PcG complexes called PRC2 and PRC1 (Polycomb Repressive Complex) and two TrxG complexes (TAC 1 and BRM) have been biochemically purified (reviewed in [10]). The PRC1 complex contains the PcG proteins Polycomb (PC), Polyhomeotic (PH), Posterior Sex Combs (PSC) and dRING1, and additional polypeptides such as the DNA binding protein Zeste $[11,12]$. The PRC2 complex contains the PcG proteins Extra Sex Combs (ESC), SU(Z)12 and Enhancer of Zeste $(\mathrm{E}(\mathrm{Z}))$, a histone methyltransferase that methylates lysine 27 of histone $\mathrm{H} 3$ (H3K27me3), and the histone binding protein p55 $[13,14]$. PC is also found in another complex that contains the DNA binding protein Pipsqueak [15], ESC and $\mathrm{E}(\mathrm{Z})$ are found in a larger complex that contains Polycomb-like (PCL), the histone deacetylase RPD3 and p55 [16], and $\mathrm{E}(\mathrm{Z})$ is found in a complex that contains the deacetylase SIR2 [17]. The TrxG complex TAC1 contains $\mathrm{CBP}$, a member of the $\mathrm{CBP} / \mathrm{p} 300$ histone acetyl tranferase (HAT) family, the anti-phosphatase SBF1, and the TrxG protein TRX, which is homologous to mammalian MLL/ ALL and methylates histone $\mathrm{H} 3$ on lysine 4 (H3K4me) [18-20]. Lastly, the BRM complex contains the TrxG proteins BRM, Osa and Moira. It is related to the yeast SWI/ SNF ATP-dependent chromatin remodeling complex, sharing four polypeptides with it, among which is the ATPase BRM [21]. It also contains BAP111, an HMGB protein that binds nonspecifically in the minor groove of the double-helix, thus bending the DNA $[22,23]$.

In Drosophila, the PcG and TrxG proteins bind overlapping sequences called Polycomb/Trithorax Response Elements (PRE/TREs) (reviewed in [4]). Two PRE/TREs (Fab-7 and the Hedgehog PRE/TRE) have been demonstrated to be true maintenance elements (ME), i. e. to control the maintenance of activation or repression of target loci through cell division $[24,25]$. A major issue is to understand how
PcG and TrxG complexes are specifically recruited to ME. On the one hand, the specific recruitment of these complexes could be achieved by recognition of posttranslationally modified histone tails. For example, PC recognizes $\mathrm{K} 27$ methylation of $\mathrm{H} 3$ via its chromodomain. Hence, PRC1 may be recruited to chromatin by the recognition of the H3K27me3 mark laid down by PRC2 through $\mathrm{E}(\mathrm{Z})[26]$. Furthermore, the methyl-transferase activity of $\mathrm{E}(\mathrm{Z})$ is required for correct repression of Hox genes, suggesting that this histone modification is actually related to gene regulation [14]. On the other hand, DNA binding proteins such as Zeste, GAF (GAGA factor), PHO (Pleiohomeotic), the HMG-box protein DSP1 (Dorsal Switch Protein 1) and Pipsqueak, which are present at some $\mathrm{ME}$, also seem to be involved in the specific recruitment of PcG and TrxG [15,27-31]. Indeed, their various combinations and associations with co-factors could make complex binding more specific.

In a large screen to identify modifiers of $\operatorname{tr} x G$ mutations, 6 genes previously identified as $P c G$ genes ( $A s x, E(z), E(P c)$, $P s c, S c m$ and $S u(z) 2)$ were isolated as enhancers of $\operatorname{tr} x G$ phenotypes [32]. The authors suggested that the corresponding genes be renamed "Enhancers of trithorax and Polycomb" (ETP) to account for their role both in repression and activation of Hox genes. Further studies identified other ETP proteins, among which is GAF [29,33], or $\mathrm{PHO}$, which directly binds a PC-containing complex as well as the BRM complex [34]. The chromodomain protein Corto [35,36] and the HMGB protein DSP1 [37] also behave as ETP. Indeed, a loss-of-function allele of corto enhances the macrochaete phenotype of the $\operatorname{trx} G$ gene osa as well as the Polycomb phenotype of the PcG genes mxc, Pc, Pcl, ph and the ETP genes E(z) and Scm [35,38]. On the other hand, a $d s p 1$ null allele enhances the haltere to wing transformation of several trxG mutants ash1, brm, osa, trx), whereas male hemizygotes for this allele exhibit transformation of the A4 segment into a more posterior one, which is a Polycomb phenotype [37]. Thus, dsp1 also behaves like an ETP. To date, little information regarding the mode of action of ETP has become available. No ETP has yet been found in TrxG complexes. Some of them belong to PcG complexes (such as E(Z), PSC and SCM) but most of them (such as ASX, Corto, GAF and SU(Z)2) have not been found in PcG complexes to date. However, in embryonic extracts, Corto co-immunoprecipitates with ESC and PC, while SU(Z)2 and GAF co-immunoprecipitate with PC, suggesting that these ETPs can transiently interact with PcG complexes [29,36,39]. How ETPs promote either the activation or the repression of a defined target gene is an open question.

To understand better the role of ETP, we analyzed the interaction between Corto and DSP1. We show that both proteins co-localize at 91 sites on Oregon- $R$ polytene chro- 

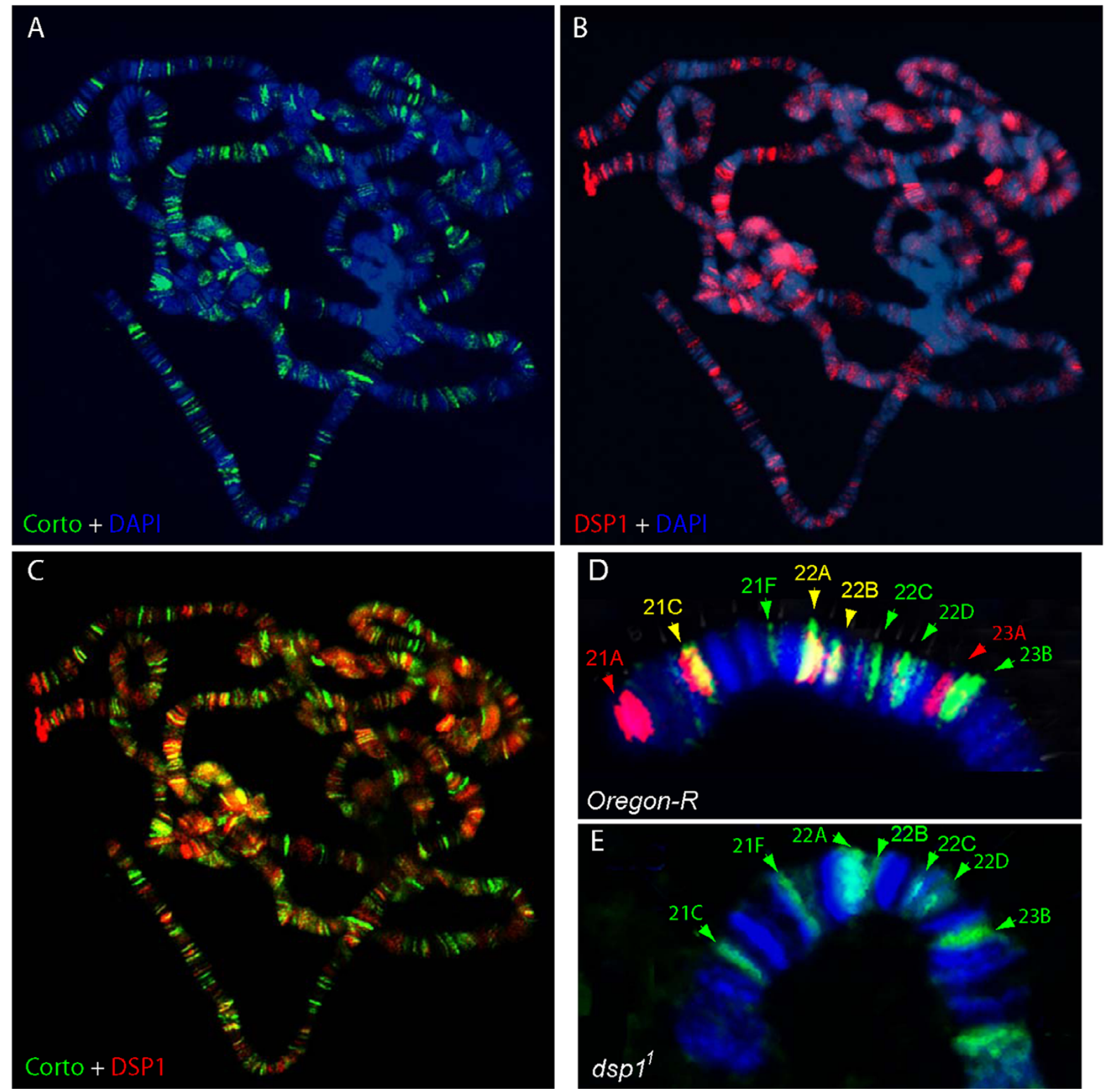

Figure I

Immunofluorescence detection of Corto and DSP I on polytene chromosomes. (A-C) Simultaneous detection of Corto (green) and DSPI (red) on Oregon- $R$ polytene chromosomes stained with DAPI (blue). (D, E) Magnification of chromosome $2 \mathrm{~L}$ end of Oregon-R (D) or $d s p I^{\prime}(\mathrm{E})$ labeled with anti-Corto (green) and anti-DSPI (red). Sites shared by DSPI and Corto in Oregon- $R$ are yellow.

mosomes. These include $84 \mathrm{~B}$, which corresponds to the distal part of the ANTP-complex. In addition, Corto and DSP1 co-immunoprecipitate in embryonic extracts and directly interact through the HMG-boxes of DSP1. Moreover, we show that the corto and $d s p 1$ genes interact and that corto, like dsp1, is directly involved in the regulation of the Hox gene Scr. Chromatin immunoprecipitation experiments indicate that Corto, like DSP1, localizes on a $10 \mathrm{~kb}$ $X b a \mathrm{I}$ ME of the Scr cis-regulatory sequences. On the basis of our results, we propose that both proteins interact on 

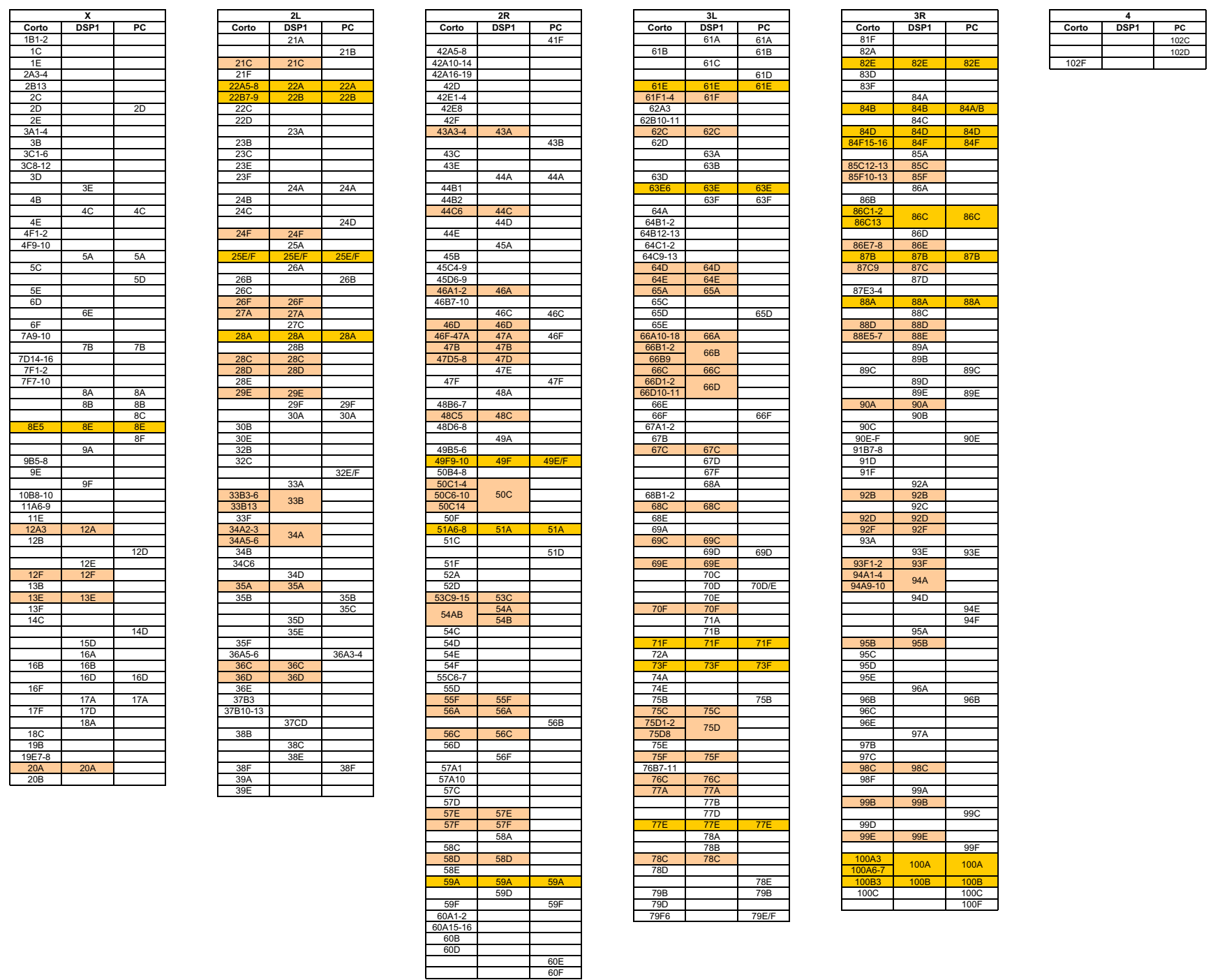

Figure 2

Comparison of Corto, DSPI and PC localizations on polytene chromosomes of Oregon- $R$ wild-type strain.

chromatin to regulate a subset of common targets including Scr.

\section{Results \\ DSPI and Corto co-localize on polytene chromosomes}

To address the genomic targets shared by Corto and DSP1, we first examined their binding on polytene chromosomes. Corto was previously shown to bind polytene chromosomes at many discrete euchromatic sites and to share these binding sites partially with PcG proteins such as PC and PH, or with ETPs such as E(Z), SCM and GAF [36]. Similarly, DSP1 binds polytene chromosomes at multiple loci and partially co-localizes with $\mathrm{PH}$ [31]. Simultaneous detection of Corto and DSP1 on chromosomes enabled us to reveal many overlapping sites (Figure $1 \mathrm{~A}-\mathrm{C})$. Precise localization of Corto and DSP1 on the pol- ytene chromosomes of Oregon- $R$ flies revealed 270 euchromatic sites of antibody staining for Corto and 173 for DSP1. These sites are listed in Figure 2 and compared with the PC sites previously determined using the same strain and staining conditions [40]. On Oregon- $R$ polytene chromosomes, 91 sites are shared by Corto and DSP1. Moreover, PC shares 40 sites with Corto and 42 sites with DSP1. Lastly, 24 sites are simultaneously occupied by the three proteins, notably $84 \mathrm{~B}$, which corresponds to the distal part of the ANTP-complex.

To examine whether DSP1 plays a role in Corto recruitment, we looked at the localization of Corto in the $d s p 1^{1}$ homozygote mutant strain, which is devoid of DSP1 protein [37]. No modification of Corto binding sites was observed in this strain, indicating that the DNA-binding 

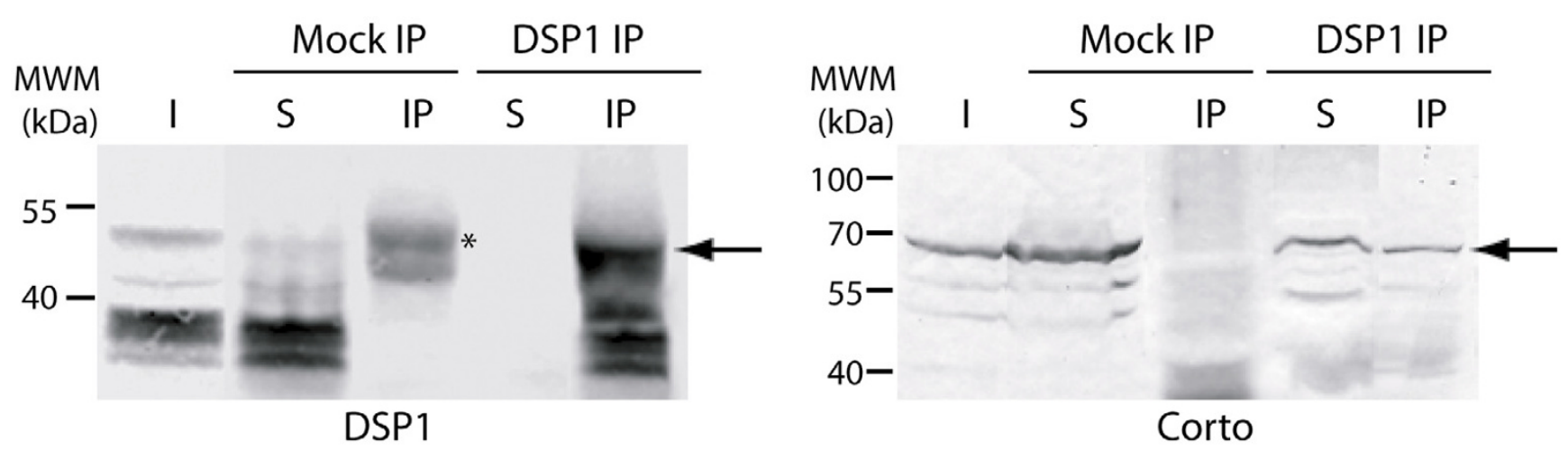

Figure 3

Corto and DSPI interact in vivo. Co-immunoprecipitation of Corto with DSPI. Protein extracts from 0-14 hour-old $w^{\prime / / 8}$ embryos were incubated either with rabbit serum (mock IP) or with anti-DSPI antibodies (DSPI IP). Western blotting was performed using rabbit anti-DSPI antibodies (left) or rat anti-Corto antibodies (right). The arrows indicate the full-length DSPI protein $(50 \mathrm{kDa})$ and Corto $(68 \mathrm{kDa})$, respectively. I : Input ; S : supernatant; IP : immunoprecipitated material; *: rabbit IgG. Note that full-length DSPI and degradation products were retained on the protein A-agarose/anti-DSPI beads.

protein DSP1 is dispensable for Corto recruitment to chromatin (Figure 1D-E).

\section{DSPI and Corto are parts of a common complex in embryos and interact directly}

We also investigated whether Corto and DSP1 belong to a same molecular complex in vivo by performing co-immunoprecipitation assays using extracts from 0-14 hour-old embryos. As shown in Figure 3, Corto co-immunoprecipitated with DSP1, indicating that DSP1 and Corto are physically associated in embryos.

Next, we asked whether DSP1 and Corto interact directly. First, DSP1 was submitted to far-western analysis using full-length radiolabeled Corto as a probe. The 386 amino acid DSP1 protein exhibits two polyglutamine series located in the 1-155 region, two HMG-boxes (HMG-A box: amino acids 171 to 246; HMG-B box: amino acids 258 to 336 ) and an acidic tail. As shown in Figure 4A, Corto was retained on full-length DSP1. In order to identify the domain(s) of interaction in the DSP1 protein, we used several truncated forms of DSP1. Neither deletion of the $\mathrm{NH}_{2}$-terminal polyglutamine regions nor that of the COOH-terminal acidic tail impaired Corto binding (see B22, C8, D16, E5, F33, J11, M2). In contrast, Corto did not bind to G81, L5 or N4. Our results allowed us to conclude that the minimal DSP1 sequence needed for Corto binding was an intact HMG-box preceded by twelve amino acids (F33 and J11 rather than G81 or L5).

The reverse experiment, $i$. e. migration and transfer of the GST-Corto fusion proteins incubated with radiolabeled DSP1, gave no conclusive results owing to the difficulty in renaturing Corto. We showed previously that the only noticeable domain of the 550 amino acid Corto protein is a chromodomain located in the $\mathrm{NH}_{2}$-terminal half (aminoacids 107 to 203) [36]. In order to characterize the Corto domains interacting with DSP1, we performed GST pull-down experiments using full-length or truncated forms of Corto fused to GST and radiolabeled full-length DSP1. The results are shown in Figure 4B. DSP1 was retained by the full-length Corto protein, corroborating the far-western results with DSP1. Moreover, DSP1 was retained by a GST fusion protein containing the $\mathrm{NH}_{2}$-terminal half of Corto (GST-C1/324), but was not detectably retained on the COOH-terminal half (GSTC325/550 and GST-C440/550). Interestingly, DSP1 was not retained on the Corto chromodomain (GST-C127/203).

Taken together, these results indicate that, in vitro, DSP1 and Corto directly interact through either the HMG-box A or the HMG-box B of DSP1 on the one hand, and the amino-terminal half of Corto on the other.

\section{corto and dsp I interact genetically and participate in Sex} comb reduced (Scr) regulation

To determine whether corto and $d s p 1$ are involved in common functions, we analyzed their genetic interactions. $d s p 1^{1}$ hemizygous males present several homeotic transformations, notably a partial transformation of T1 to T2 leg as shown by a reduced sex comb (average size 6 teeth, rather than the 10 to 11 in a wild-type strain), and a partial transformation of A6 to A5 as shown by the presence of bristles on the A6 sternite ( $25 \%$ of $d s p 1^{1}$ males exhibit this phenotype) [37]. These phenotypes are related to a role of $d s p 1$ in the regulation of $S c r$ and $A b d B$, respectively. We observed that loss of corto strongly suppresses both homeotic phenotypes (Table 1). Together, these data sug- 
A

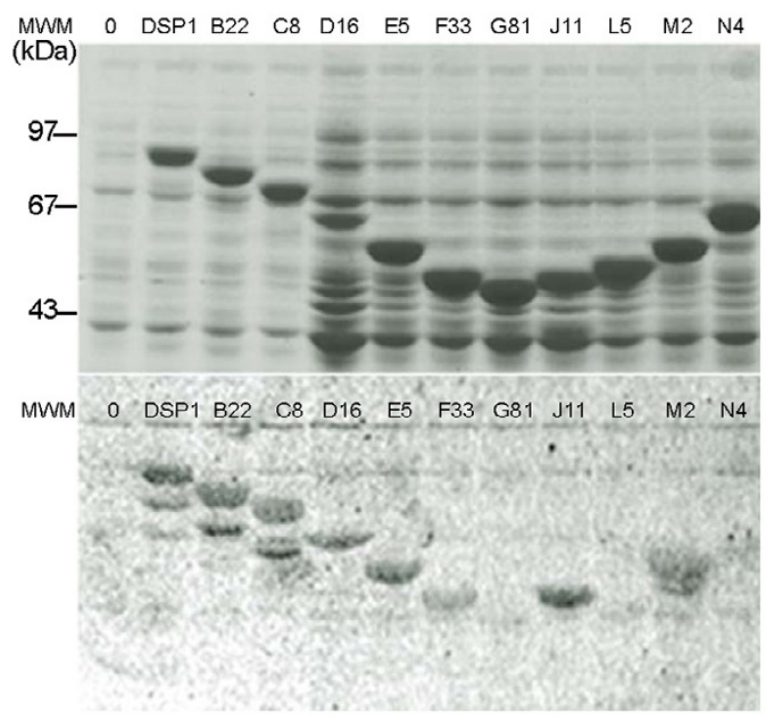

Corto binding

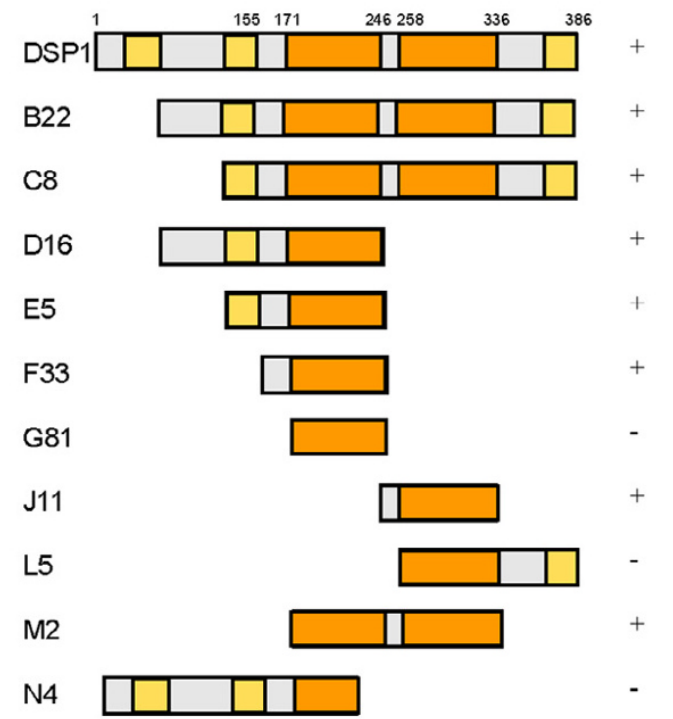

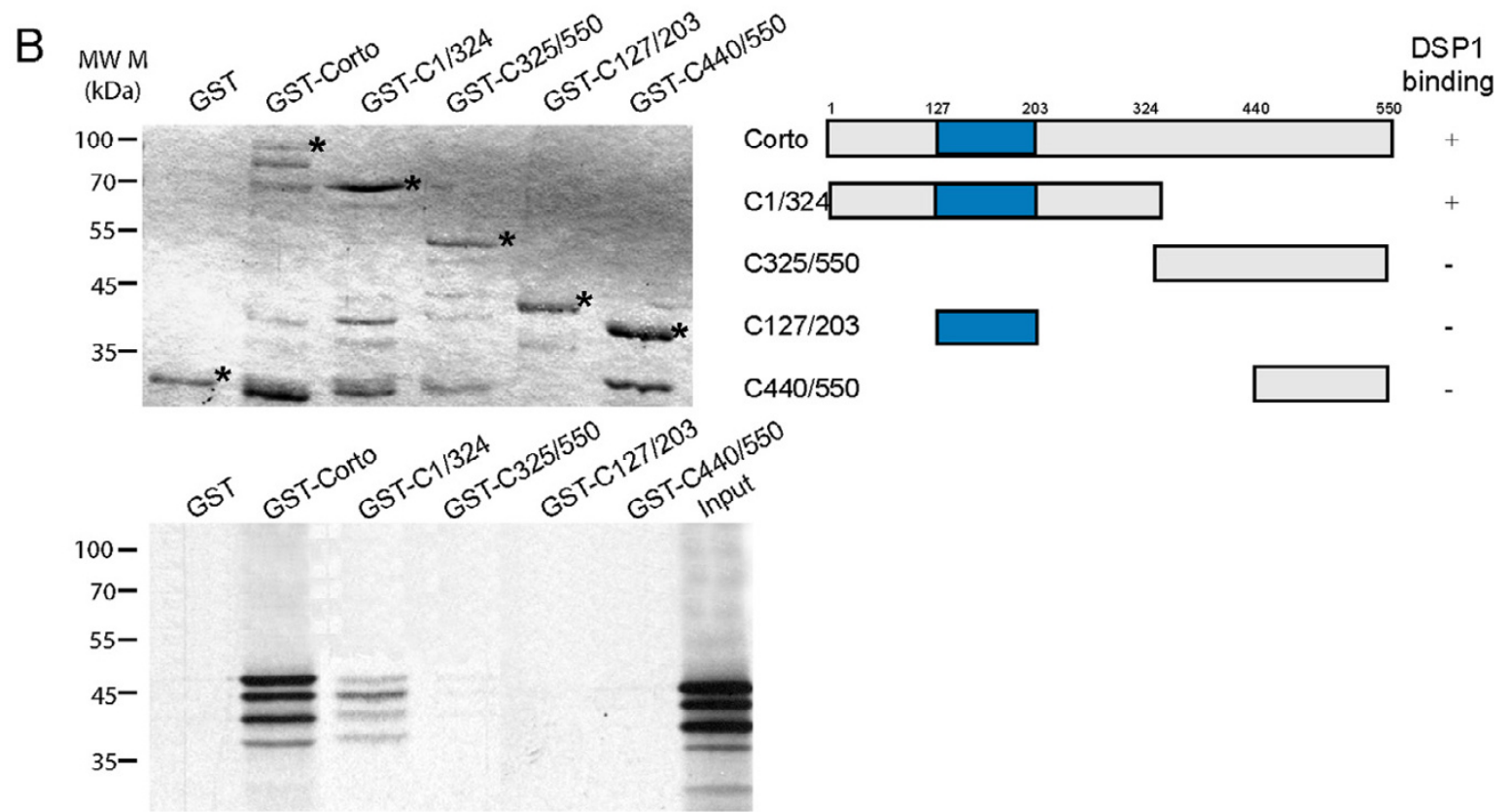

\section{Figure 4}

Corto and DSPI interact in vitro. (A) Far-western assays. Left, top: Coomassie-stained SDS-PAGE of the MBP-DSPI fusion proteins. Left, bottom: Phosphorimager scan of the membrane after transfer of the proteins and incubation with radiolabeled Corto. Right: Schematic representation of DSPI and DSPI truncated forms (orange: HMG-A and HMG-B boxes; yellow: polyglutamine series and acidic tail). Corto is retained on MBP-DSPI and on B22, C8, DI6, E5, F33, JII and M2 MBP-DSPI truncated forms but not on G8I, L5 and N4 MBP-DSPI truncated forms. (B) GST pull-down assays Left, top: Coomassie blue staining of GST and GST-Corto fusion proteins (labeled with asteriks). Left, bottom: Autoradiography. ${ }^{35}$ S-labeled DSPI was retained on GST-Corto and GST-CI/324 proteins and not on GST-C325/550, GST-CI 27/203 or GST-C440/550. Input: I/5 of the total radioactivity was loaded. Note that the full-length DSPI protein as well as the truncated forms (degradation products or abortive translations) are retained on GST-Corto and GST-CI/324. Right : Schematic representation of Corto (blue : chromodomain). 
Table I: Genetic interactions between dspI and corto

\begin{tabular}{|c|c|c|c|c|}
\hline Genotype & Legs observed & $\begin{array}{c}\text { average sex comb teeth on } \\
\text { the TI leg }\end{array}$ & Males observed & A6 to $\mathrm{A} 5(\%)$ \\
\hline$+/ Y$ & 52 & II.I & 36 & 0 \\
\hline$d s p / 1 / Y ;+/+$ & 40 & 6.0 & 46 & 25 \\
\hline +/Y; corto $420 /+$ & 61 & 10.5 & 37 & 0 \\
\hline +/Y; corto $07128 /+$ & 48 & 11.2 & 34 & 0 \\
\hline dsp/I/Y; corto $420 /+$ & 113 & 9.0 & 68 & 0 \\
\hline dsp/l'/Y; corto $07 / 28 /+$ & 31 & 9.0 & 69 & 3 \\
\hline
\end{tabular}

Homozygous $d s p /$ I females were crossed with either corto420/TM3 or corto $07 / 28 / T M 3$ males, or with Oregon-R males as controls. The resulting male progeny was scored for two homeotic transformations previously observed in dsp I' mutants: (i) transformation of TI leg into T2 leg monitored by the size of the sex comb, (ii) transformation of segment $A 6$ into segment $A 5$ as revealed by the presence of bristles on $A 6$ sternites.

gest that corto is involved with $d s p 1$ in Hox gene regulation. Notably, they suggest that both corto and $d s p 1$ regulate $S c r$ in the $\mathrm{T} 1$ leg imaginal disc.

Interestingly, $d s p 1^{1}$ was previously shown to cause partial suppression of the gain-of-function allele $\mathrm{Scr}^{S}$ [37]. Better to understand the relationship between corto and $d s p 1$ in the regulation of $S c r$, we analyzed genetic interactions between corto and Scr. We first used two loss-of-function alleles of $S c r$, the EMS-induced $S c r^{1}$ allele and $D f(3 R) S c x 4$, a deficiency of the distal end of the Scr cis-regulatory regions. Males heterozygous for either allele $\left(\mathrm{Scr}^{1} /+\right.$ or $\left.D f(3 R) S x c^{4} /+\right)$ exhibit a reduction in the size of the sex comb on the first leg with an average number of 6.5 teeth per comb. No modification of this kind was observed in $S_{c r}{ }^{1} /$ corto $^{-}$or $D f(3 R) S x c^{4} /$ corto $^{-}$males (data not shown). We next checked the interactions between corto and the gainof-function allele Scr AntpScx (Table 2). In this allele, the insertion of a transposable element near the Antp P1 promoter disturbs $\mathrm{Scr}$ silencing in the T2 and T3 leg imaginal discs [3]. Indeed, 39\% of Antpscx/+ males exhibited an ectopic sex comb on the $\mathrm{T} 2 \mathrm{leg}$, i.e. a transformation of $\mathrm{T} 2$ leg into $\mathrm{T} 1 \mathrm{leg}$. This percentage increased to $83 \%, 95 \%$ or $100 \%$, depending on the corto allele, in Antpscx/corto males (Table 2). These results show that corto, like PcG genes, participates in the maintenance of $\mathrm{Scr}$ repression in the T2 and T3 leg imaginal discs and corroborates our previous results showing that corto interacts with some $P c G$ genes for this ectopic sex comb phenotype $[35,38]$.

Table 2: Genetic interactions between corto and Scr

\begin{tabular}{lcc}
\hline Genotype & Males observed & T2 to T1 (\%) \\
\hline Antp ${ }^{S c x} /+$ & 163 & 38.6 \\
Antp $^{S c x} /$ corto $^{420}$ & 177 & 83.0 \\
Antp $^{S c x} /$ corto $^{07 / 28}$ & 179 & 94.9 \\
Antp $^{S c x} /$ corto $^{L 1}$ & 173 & 100.0
\end{tabular}

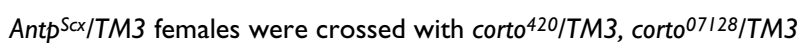
or cortoll/TM3 males, or $w^{1 / 18}$ males as controls. Reciprocal crosses were also performed. As similar results were obtained, they were pooled. The resulting male progeny was scored for transformation of T2 into TI leg as revealed by the presence of ectopic sex comb teeth.

\section{Corto and DSPI bind the same region within the $10-\mathrm{kb}$} Xbal fragment of the Scr regulatory sequences

To analyze the roles of Corto and DSP1 in Scr regulation further, we addressed their binding to Scr cis-regulatory sequences by chromatin immunoprecipitation experiments (XChIP). In S2 cells, XChIP followed by Southern analysis has previously shown that DSP1 binds two 1-kb sequences in the central part of a 10-kb XbaI fragment located about 37-kb upstream from the Scr transcription start [41]. Formaldehyde cross-linked chromatin from 014 hour-old embryos or S2 cells was immunoprecipitated with either DSP1 antibodies, Corto antibodies or rabbit serum as a control. Binding of Corto or DSP1 was analyzed by PCR amplification of 7 sequences (S1 to S7) covering the central region of the 10-kb XbaI fragment and two sequences (SL and SR) located on each side of this fragment. The results are shown in Figure 5. No binding of Corto or DSP1 was observed on the SL and SR fragments. DSP1 did not bind fragments S1 to S7 in embryos but bound them in S2 cells, corroborating previous results [41]. Maximum enrichment was observed for S3 and S7, which overlap the two 1-kb sequences where DSP1 binding was previously observed [41]. Corto binding was observed in both embryos and S2 cells. In embryos, we observed two main peaks of binding (S1-S2 and S6-S7). Interestingly, in S2 cells, Corto covered the entire S1 to S7 region. Therefore, the enlargement of the Corto binding domain was correlated with the presence of DSP1 on the same fragment.

\section{Discussion}

We report in the present work that the two ETPs corto and $d s p 1$ interact genetically and that the proteins they encode (i) directly interact in vitro, (ii) co-immunoprecipitate in embryos and (iii) co-localize on 91 sites in salivary gland polytene chromosomes. These results suggest that the proteins are simultaneously involved in the regulation of several target genes. DSP1 can bind Corto through one of the two HMG-boxes that also mediate DNA binding. It has been suggested that during nucleoprotein complex formation, the HMG-box B of HMGB bends DNA whereas the 
HMG-box A mediates interaction with transcription factors, thus promoting their contact with targets [22]. DSP1 seems to follow that scheme to enhance the binding of transcription factors as Dorsal or Bicoid to DNA $[42,43]$. What therefore could be the role of the DSP1-Corto interaction in the regulation of common targets? First, DSP1 could bring Corto to the chromatin, where it could further interact with other partners. These partners could be PcG factors or GAF, which have previously been shown to interact with Corto [36]. Nevertheless, this hypothesis is unlikely since we observed no modification of Corto binding to polytene chromosomes in the $d s p 1^{1}$ strain. Second, DSP1 could inhibit the interaction between Corto and PcG factors or GAF, thus preventing the silencing of targets that bind both proteins. Third, Corto could modify the DNA bending ability of DSP1 and thus modulate its interaction with other factors, for example TrxG complexes. Indeed, the $d s p 1$ gene was previously shown to interact with the $\operatorname{Tr} x G$ genes trx and brm [37] Our results do not allow us to discriminate between these last two, non-exclusive

possibilities.

We also report that the Hox gene Scr is a common target of Corto and DSP1. Both proteins bind a 10-kb XbaI fragment located 37-kb upstream of the Scr transcription start. Genetic studies have shown that this fragment is required for $S c r$ function in the embryo and in the imaginal disc [44-46]. In embryos, it restricts the expression of a Scr-lacZ fusion gene to the labial and prothoracic segments [44], whereas in larvae it is required for Scr expression in the first leg imaginal disc and for Scr silencing in the second and third leg imaginal discs [45]. Interestingly, the function of the 10-kb XbaI fragment is sensitive to a subset of PcG and TrxG mutations [47] and has been genetically characterized as an upstream maintenance element of $\mathrm{Scr}$ [46]. At the end of embryogenesis, the Scr expression domain is restricted to the labial and prothoracic segments. In consequence, the mean state of this $\mathrm{ME}$ in the whole embryo would be silenced. We can thus assume that the global situation in embryos mimics that of the T2 and T3 leg imaginal discs. Conversely, since Scr is expressed in S2 cells (data not shown), we propose that the situation in S2 cells rather mimics that of T1 leg imaginal disc cells. Hence, Corto, which is present on the Scr ME whether active (S2 cells) or silenced (embryos), could be present on this ME in all three leg imaginal discs. On the other hand, DSP1, which is present on the ME in S2 cells but not in embryos, could bind the ME only in cells where this element is active, hence in $\mathrm{T} 1$ leg imaginal disc cells. We thus propose that both Corto and DSP1 proteins localize on this Scr ME in the first leg imaginal disc.

Some $\operatorname{tr} x G$ mutants as well as the $d s p 1$ null mutant exhibit a reduced sex comb and our previous work has shown that $d s p 1$ interacts with certain $\operatorname{tr} x G$ genes and regulates $S c r$ expression in T1 discs [2,37]. HMGB, the vertebrate homologue of DSP1, has been reported to activate and stabilize the TFIID-TFIIA-promoter complex in vitro [48] and some TrxG factors have been shown to interact with the RNA polymerase II complex, thus facilitating transcriptional elongation $[49,50]$. This leads us to propose that in the T1 leg imaginal disc, DSP1 facilitates the interaction between a TrxG complex and the transcription machinery, thus maintaining Scr activation. Moreover, Corto has been shown to interact with PcG complexes [36]. The binding of Corto to DSP1 could then impede the interaction between Corto and PcG complexes, thus limiting their recruitment. Therefore, the interaction between the two proteins on the ME would lead to a level of Scr transcription compatible with T1 identity. Conversely, in the T2 and T3 leg imaginal discs, since DSP1 does not bind the ME, Corto would be able to interact with PcG complexes, thus enhancing the silencing of Scr.

\section{Conclusion}

In summary, we have shown that the two ETPs Corto and DSP1 directly interact and are simultaneously found on a Scr ME when active, whereas Corto alone is found on the same ME when inactive. Our data suggest that different combinations of ETP favor the recruitment of either PcG or TrxG complexes, participating in the maintenance of the silenced or active state of ME.

\section{Methods}

\section{Drosophila strains and genetics}

Flies were raised on standard medium at $25^{\circ} \mathrm{C}$ except for the $d s p 1$ strain, which was maintained at $22^{\circ} \mathrm{C}$. All mutations and chromosome aberrations used are described in Flybase [51]. Oregon- $R$ or $w^{1118}$ were used as wild-type reference strains. $d s p 1^{1}$ is a null allele of $d s p 1$, which is maintained as a homozygous strain [37]. corto ${ }^{420}$, corto $^{07128}$ and $\operatorname{corto}^{L 1}$ are loss-of-function alleles: a deficiency, a P-element insertion and an uncharacterized mutation obtained by EMS mutagenesis, respectively. These alleles were balanced over TM3.

\section{Localization of proteins on polytene chromosomes}

Co-immunostaining of Oregon- $R$ or $d s p 1^{1}$ polytene chromosomes was performed as previously described using rabbit affinity purified anti-DSP1 (1:150) and rat antiCorto $(1: 40)$ as primary antibodies [36]. Secondary antibodies (Alexa Fluor ${ }^{\circledR} 594$ goat anti-rabbit IgG and Alexa Fluor ${ }^{\circledast} 488$ goat anti-rat IgG, Molecular Probes) were used at a 1:1000 dilution. To determine the precise localization of Corto and DSP1, immunostainings were performed separately on squashes of Oregon- $R$ chromosomes using rabbit affinity-purified anti-DSP1 (1:150) or rabbit antiCorto (1:40) as described [40]. 
A
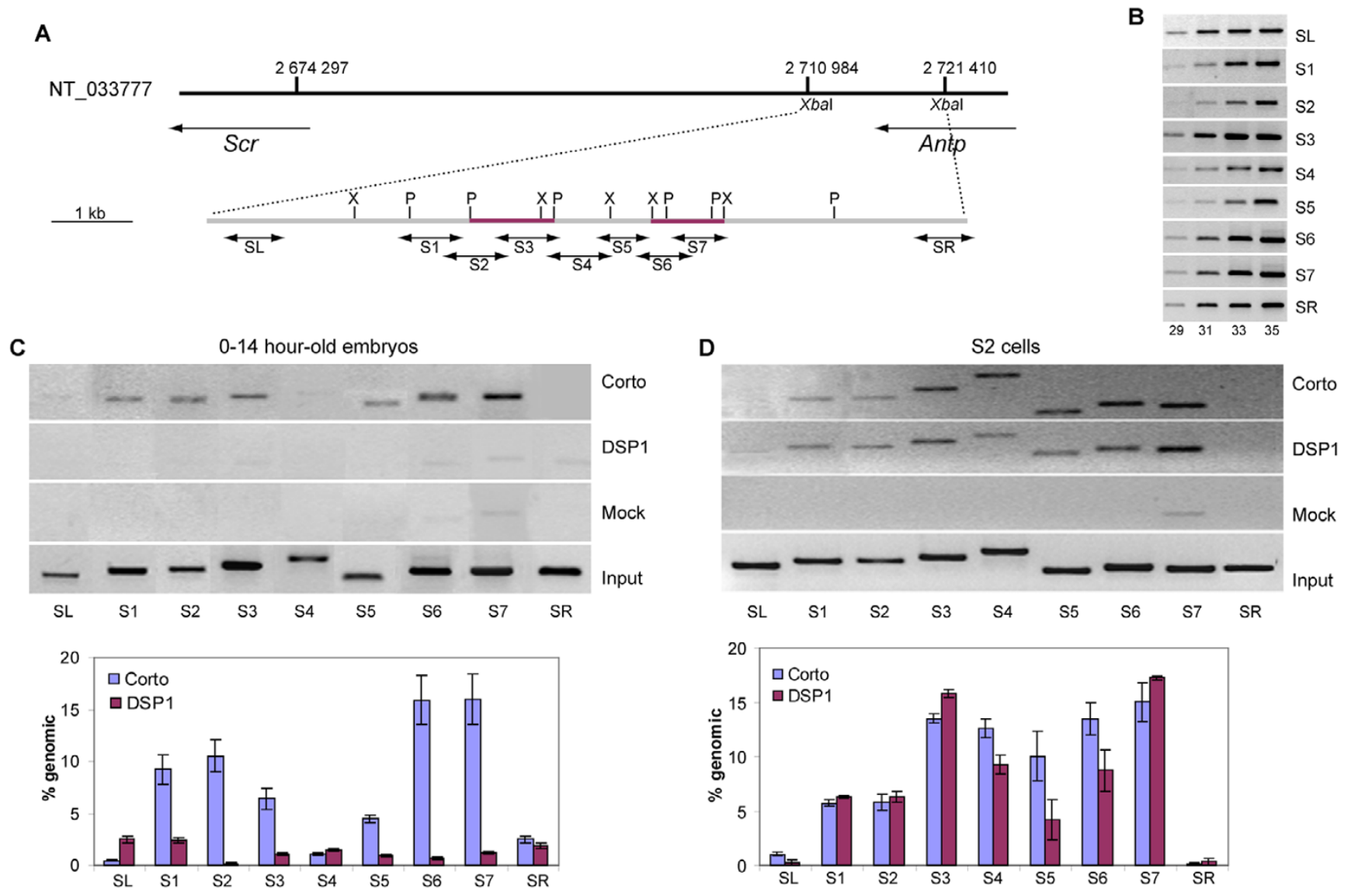

\section{Figure 5}

Binding of Corto on the Scr I 0-kb Xbal fragment. (A) The I0-kb Xbal Scr fragment is located about 37-kb upstream from the transcription start site. Numbers refer to NT_033777, i.e. the access number of the complete sequence of the Drosophila melanogaster 3R chromosome. The 7 internal sequences (SI to S7) and the two distal sequences (SL and SR) were amplified with specific primers as described in Methods. The Pvull and Xmnl fragments, where DSPI has been previously shown to bind, are in purple [4I]. (B) To determine the linear range of amplification, PCR samples were taken at the $29^{\text {th }}, 3 \mathrm{I}^{\text {st }}, 33^{\mathrm{rd}}$ and $35^{\text {th }}$ PCR cycles. (C-D) Chromatin immunoprecipitation analysis of 0-14 hour-old embryos (C) or S2 cells (D) using rabbit anti-Corto, rabbit anti-DSPI or rabbit serum as a control (mock). The 3 Ist cycle samples were loaded on a I\% agarose gel. The PCR products were quantified using Image J software and expressed as a percentage of the total input DNA. The diagrams represent the mean of 3 independent experiments.

\section{Co-immunoprecipitation assays}

Embryos (0-14 hour-old $\left.w^{1118}, 2 \mathrm{~g}\right)$ were crushed in $4 \mathrm{ml}$ of $50 \mathrm{mM}$ Tris $\mathrm{pH} 7.5,150 \mathrm{mM} \mathrm{NaCl}, 1 \% \mathrm{NP} 40,0.1 \%$ SDS, $1 \mathrm{mM}$ PMSF supplemented with protease inhibitors (Roche). After sonication and high-speed centrifugation, the extracts were pre-cleared with protein A-agarose beads and incubated overnight at $4^{\circ} \mathrm{C}$ with $10 \mu \mathrm{g}$ of anti-DSP1 affinity-purified antibodies or $10 \mu \mathrm{l}$ of rabbit serum. Following extensive washing, the beads were resuspended in Laemmli buffer and analyzed by SDS-PAGE and western blotting.

\section{Far-western and GST pull-down assays}

Most of the vectors expressing full-length or truncated forms of MBP-DSP1 or GST-Corto fusion proteins have been described previously [36,37]. pGEX-C1/324 was obtained by digestion of pEG-Corto with EcoRI and PvuII and sub-cloning the resulting 1-kb fragment into pGEX4T-1. pGEX-C325/550 was obtained by PCR amplification of a $0.7 \mathrm{~kb}$ DNA fragment from pBS-Corto using oligonucleotides 5'-CCG GAA TTC CGG GCT GCG GCC CAG GCC TCG ATA GCC-3' and 5'-CCG CTC GAG CGG CAC GTT GTA GCA GGA GAT CTG CGG-3', digestion with EcoRI and XhoI, and sub-cloning into pGEX4T-1. In vitro synthesis of radiolabeled proteins was performed using the $\mathrm{TNT}^{\circledast}$ coupled reticulocyte lysate system (Promega) and ${ }^{35}$ S methionine. Far-western and GST pulldown assays were performed as previously described [36,37]. 
Immunoprecipitation of crosslinked chromatin (XChIP) and semi-quantitative PCR analysis

Formaldehyde cross-linking of Drosophila S2 cell or 0-14 hour-old $w^{1118}$ embryo chromatin and chromatin immunoprecipitation were performed as described [52]. Immunoprecipitation of purified chromatin was performed either with rabbit Corto antibodies (1:20), affinity-purified DSP1 antibodies (5 $\mu \mathrm{g}$ ) or rabbit serum (1:20) in 250 $\mu$ final volumes. One percent of the co-immunoprecipitated DNA was used for the PCR reactions. Nine primer pairs amplifying 500-700 bp fragments in the cis-regulatory sequences of $\mathrm{Scr}$ (NCBI accession number: NT_033777) were designed: SL forward 5'-AAA TCG GAC TGC TGC AAT TGA AGG-3', reverse 5'-AAT CCA AAA TGT TAC CCG GTG GCC-3', S1 forward 5'-GCA TCA AAA ACG AGT TAA GG-3', reverse 5'-ATA AAT CTT AGC TGC CTG CG-3', S2 forward 5'-CGC AGG CAG CTA AGA TTT ATG G-3', reverse 5'-CCG TTT GGG ATA AAC TTG GG-3', S3 forward 5'-GTT CCC AAG TTT ATC CCA AAC G-3', reverse 5'-GCT GAG GAG AAA GCT TCT GG-3', S4 forward 5'CCA GAA GCT TTC TCC TCA GC-3', reverse 5'-CGG TAG CTG ATT TCG GAA AG-3', S5 forward 5'-CTT TCC GAA ATC AGC TAC CG-3', reverse 5'-TAT TTC CTC TCG AAC CCA CG-3', S6 forward 5'-GAG AGG AAA TAT GCA CTG GC-3', reverse 5'-GAA CGG ATC CAA ACC AAA CC-3', S7 forward 5'-AAA AGC TCT GAA AGT GTT AAG TGG C-3', reverse 5'-AAT GGC CCG AAT GAA GAA GC-3', and SR forward 5'-TCT ATC GTT CGG TTC AAT GGC TCC-3', reverse 5'-TTG GAA AAT GCC CAG CAG ACA TCC-3'. The PCR schemes were as follows: $94^{\circ} \mathrm{C}$ for $3 \mathrm{~min} ; 94^{\circ} \mathrm{C}$ for 1 $\min , 57^{\circ} \mathrm{C}(\mathrm{S} 3, \mathrm{~S} 6), 58^{\circ} \mathrm{C}(\mathrm{S} 4), 59^{\circ} \mathrm{C}(\mathrm{S} 1), 60^{\circ} \mathrm{C}(\mathrm{SL}, \mathrm{S} 2$, $\mathrm{S} 5, \mathrm{~S} 7, \mathrm{SR}$ ) for one $\mathrm{min}, 35$ times, $72^{\circ} \mathrm{C}$ for one $\mathrm{min} ; 72^{\circ} \mathrm{C}$ for $10 \mathrm{~min}$. PCR samples were taken at the $29^{\mathrm{th}}, 31^{\mathrm{st}}, 33^{\mathrm{rd}}$ and $35^{\text {th }}$ cycles to ensure that quantifications were performed in the linear range. PCR gels were photographed with a Biorad Geldoc system and quantified using ImageJ software (NIH). The results were normalized against the mock immunoprecipitation and presented as percentages of input DNA.

\section{Authors' contributions}

JS performed the fluorescent immunodetection of DSP1 and Corto on polytene chromosomes and chromatin immunoprecipitation assays together with MB. MD and DL performed the genetic interactions between corto and dsp1. EMV performed the GST pull-down assays. AD performed the far-western experiments. LB and IZ performed the immunodetection of DSP1 and Corto on polytene chromosomes and determined the Corto and DSP1 binding sites. FP performed the genetic interaction between corto and Scr. The manuscript was written by FP; all the coauthors reviewed and approved the final manuscript.

\section{Acknowledgements}

The authors wish to thank Valérie Ribeiro, Nicole Salmon and Andrée Soulas for excellent technical assistance, and Sébastien Bloyer, Jean-Michel Gib- ert and Neel Randsholt for fruitful discussions and careful reading of the manuscript. JS was supported by fellowships from the Ministère de la Recherche and from Association pour la Recherche contre le Cancer. This work was supported in part by Ligue Locale 4 I contre le Cancer and Fondation pour la Recherche Médicale to DL and MD.

\section{References}

I. Lewis EB: A gene complex controlling segmentation in Drosophila. Nature 1978, 276(5688):565-570.

2. Ingham PW: A clonal analysis of the requirement for the trithorax gene in the diversification of segments in Drosophila. J Embryol Exp Morphol 1985, 89:349-365.

3. Kennison JA, Tamkun JW: Dosage-dependent modifiers of polycomb and antennapedia mutations in Drosophila. Proc Natl Acad Sci U S A 1988, 85(2I):8I 36-8I40.

4. Brock HW, Fisher CL: Maintenance of gene expression patterns. Dev Dyn 2005, 232(3):633-655.

5. Moazed D, O'Farrell PH: Maintenance of the engrailed expression pattern by Polycomb group genes in Drosophila. Development 1992, I I 6(3):805-810.

6. Brizuela BJ, Kennison JA: The Drosophila homeotic gene moira regulates expression of engrailed and $\mathrm{HOM}$ genes in imaginal tissues. Mech Dev 1997, 65( I-2):209-220.

7. Randsholt NB, Maschat F, Santamaria P: polyhomeotic controls engrailed expression and the hedgehog signaling pathway in imaginal discs. Mech Dev 2000, 95(1-2):89-99.

8. Kuzin B, Tillib S, Sedkov Y, Mizrokhi L, Mazo A: The Drosophila trithorax gene encodes a chromosomal protein and directly regulates the region-specific homeotic gene fork head. Genes Dev 1994, 8(20):2478-2490.

9. Netter S, Fauvarque MO, Diez del Corral R, Dura JM, Coen D: white+ transgene insertions presenting a dorsal/ventral pattern define a single cluster of homeobox genes that is silenced by the polycomb-group proteins in Drosophila melanogaster. Genetics 1998, I 49(I):257-275.

10. Simon JA, Tamkun JW: Programming off and on states in chromatin: mechanisms of Polycomb and trithorax group complexes. Curr Opin Genet Dev 2002, I 2(2):210-218.

II. Saurin AJ, Shao Z, Erdjument-Bromage H, Tempst P, Kingston RE: A Drosophila Polycomb group complex includes Zeste and dTAFII proteins. Nature 200I, 4I 2(6847):655-660.

12. Shao Z, Raible F, Mollaaghababa R, Guyon JR, Wu CT, Bender W, Kingston RE: Stabilization of chromatin structure by PRCI, a Polycomb complex. Cell 1999, 98(I):37-46.

13. Tie F, Furuyama T, Prasad-Sinha J, Jane E, Harte PJ: The Drosophila Polycomb Group proteins ESC and $E(Z)$ are present in a complex containing the histone-binding protein p55 and the histone deacetylase RPD3. Development 200I, I 28(2):275-286.

14. Muller J, Hart CM, Francis NJ, Vargas ML, Sengupta A, Wild B, Miller EL, O'Connor MB, Kingston RE, Simon JA: Histone methyltransferase activity of a Drosophila Polycomb group repressor complex. Cell 2002, I I I(2): 197-208.

15. Huang DH, Chang YL, Yang CC, Pan IC, King B: pipsqueak encodes a factor essential for sequence-specific targeting of a polycomb group protein complex. Mol Cell Biol 2002, 22(I7):626I-627I.

16. Tie F, Prasad-Sinha J, Birve A, Rasmuson-Lestander A, Harte PJ: A Imegadalton ESC/E(Z) complex from Drosophila that contains polycomblike and RPD3. Mol Cell Biol 2003, 23(9):3352-3362.

17. Furuyama T, Banerjee R, Breen TR, Harte PJ: SIR2 is required for polycomb silencing and is associated with an $E(Z)$ histone methyltransferase complex. Curr Biol 2004, I4(20): I8I2-182I.

18. Petruk S, Sedkov Y, Smith S, Tillib S, Kraevski V, Nakamura T, Canaani $E$, Croce CM, Mazo A: Trithorax and dCBP acting in a complex to maintain expression of a homeotic gene. Science 200I, 294(5545): | $33|-| 334$.

19. Milne TA, Briggs SD, Brock HW, Martin ME, Gibbs D, Allis CD, Hess JL: MLL targets SET domain methyltransferase activity to Hox gene promoters. Mol Cell 2002, I O(5): I I07-I I I7.

20. Nakamura T, Mori T, Tada S, Krajewski W, Rozovskaia T, Wassell R, Dubois G, Mazo A, Croce CM, Canaani E: ALL-I is a histone methyltransferase that assembles a supercomplex of proteins involved in transcriptional regulation. Mol Cell 2002, I0(5): I I I9-II 28. 
21. Papoulas O, Beek SJ, Moseley SL, McCallum CM, Sarte M, Shearn A, Tamkun JW: The Drosophila trithorax group proteins BRM, $\mathrm{ASHI}$ and ASH2 are subunits of distinct protein complexes. Development 1998, I 25(20):3955-3966.

22. Thomas JO, Travers AA: HMGI and 2, and related 'architectural' DNA-binding proteins. Trends Biochem Sci 200I, 26(3): I67-I74.

23. Papoulas O, Daubresse G, Armstrong JA, Jin J, Scott MP, Tamkun JW: The HMG-domain protein BAP I I I is important for the function of the BRM chromatin-remodeling complex in vivo. Proc Natl Acad Sci U S A 200 I, 98(1 0):5728-5733.

24. Maurange $C$, Paro R: A cellular memory module conveys epigenetic inheritance of hedgehog expression during Drosophila wing imaginal disc development. Genes Dev 2002, I 6(20):2672-2683.

25. Cavalli G, Paro R: Epigenetic inheritance of active chromatin after removal of the main transactivator. Science 1999 286(544I):955-958.

26. Wang L, Brown JL, Cao R, Zhang Y, Kassis JA, Jones RS: Hierarchical recruitment of polycomb group silencing complexes. Mol Cell 2004, I 4(5):637-646.

27. Dejardin J, Cavalli G: Chromatin inheritance upon Zeste-mediated Brahma recruitment at a minimal cellular memory module. Embo J 2004, 23(4):857-868

28. Mishra RK, Mihaly J, Barges S, Spierer A, Karch F, Hagstrom K, Schweinsberg SE, Schedl $P$ : The iab-7 polycomb response element maps to a nucleosome-free region of chromatin and requires both GAGA and pleiohomeotic for silencing activity. Mol Cell Biol 200I, 2 I(4): |3| |- |3|8.

29. Horard B, Tatout C, Poux S, Pirrotta V: Structure of a polycomb response element and in vitro binding of polycomb group complexes containing GAGA factor. Mol Cell Biol 2000, 20(9):3187-3197.

30. Hur MW, Laney JD, Jeon SH, Ali J, Biggin MD: Zeste maintains repression of Ubx transgenes: support for a new model of Polycomb repression. Development 2002, I 29(6): | 339- | 343.

31. Dejardin J, Rappailles A, Cuvier O, Grimaud C, Decoville M, Locker D, Cavalli G: Recruitment of Drosophila Polycomb group proteins to chromatin by DSPI. Nature 2005, 434(7032):533-538.

32. Gildea JJ, Lopez R, Shearn A: A screen for new trithorax group genes identified little imaginal discs, the Drosophila melanogaster homologue of human retinoblastoma binding protein 2. Genetics 2000, I 56(2):645-663.

33. Bejarano F, Busturia A: Function of the Trithorax-like gene during Drosophila development. Dev Biol 2004, 268(2):327-34l.

34. Mohd-Sarip A, Venturini F, Chalkley GE, Verrijzer CP: Pleiohomeotic can link polycomb to DNA and mediate transcriptional repression. Mol Cell Biol 2002, 22(2I):7473-7483.

35. Lopez A, Higuet D, Rosset R, Deutsch J, Peronnet F: corto genetically interacts with Pc-G and trx-G genes and maintains the anterior boundary of Ultrabithorax expression in Drosophila larvae. Mol Genet Genomics 200I, 266(4):572-583.

36. Salvaing J, Lopez A, Boivin A, Deutsch JS, Peronnet F: The Drosophila Corto protein interacts with Polycomb-group proteins and the GAGA factor. Nucleic Acids Res 2003 3 I ( I I ):2873-2882

37. Decoville M, Giacomello E, Leng M, Locker D: DSPI, an HMG-like protein, is involved in the regulation of homeotic genes. Genetics 200I, I 57( I ):237-244.

38. Kodjabachian L, Delaage M, Maurel C, Miassod R, Jacq B, Rosset R: Mutations in ccf, a novel Drosophila gene encoding a chromosomal factor, affect progression through mitosis and interact with Pc-G mutations. Embo J 1998, I 7(4): I063-1075.

39. Poux S, McCabe D, Pirrotta V: Recruitment of components of Polycomb Group chromatin complexes in Drosophila. Development 200I, I 28(I):75-85.

40. Zhimulev IF, Belyaeva ES, Makunin IV, Pirrotta V, Volkova El, Aleksey enko AA, Andreyeva EN, Makarevich GF, Boldyreva LV, Nanayev RA, Demakova OV: Influence of the SuUR gene on intercalary heterochromatin in Drosophila melanogaster polytene chromosomes. Chromosoma 2003, I I I(6):377-398.

4I. Rappailles A, Decoville M, Locker D: DSPI, a Drosophila HMG protein, is involved in spatiotemporal expression of the homoeotic gene Sex combs reduced. Biol Cell 2005, 97(10):779-785.
42. Decoville M, Giraud-Panis MJ, Mosrin-Huaman C, Leng M, Locker D: HMG boxes of DSPI protein interact with the rel homology domain of transcription factors. Nucleic Acids Res 2000, 28(2):454-462.

43. Daulny A, Rappailles A, Landemarre L, Locker D, Decoville M: DSP I interacts with bicoid for knirps enhancement. Genesis 2003 36(2): $104-113$

44. Gindhart JGJ, King AN, Kaufman TC: Characterization of the cisregulatory region of the Drosophila homeotic gene Sex combs reduced. Genetics 1995, 139(2):781-795.

45. Pattatucci AM, Kaufman TC: The homeotic gene Sex combs reduced of Drosophila melanogaster is differentially regulated in the embryonic and imaginal stages of development. Genetics 1991, I 29(2):443-46 I.

46. Southworth JW, Kennison JA: Transvection and silencing of the Scr homeotic gene of Drosophila melanogaster. Genetics 2002, I 6 I (2):733-746.

47. Gindhart JG], Kaufman TC: Identification of Polycomb and trithorax group responsive elements in the regulatory region of the Drosophila homeotic gene Sex combs reduced. Genetics 1995, I39(2):797-8|4

48. Shykind BM, Kim J, Sharp PA: Activation of the TFIID-TFIIA complex with HMG-2. Genes Dev 1995, 9(I I): I 354-I 365

49. Smith ST, Petruk S, Sedkov Y, Cho E, Tillib S, Canaani E, Mazo A Modulation of heat shock gene expression by the TACI chromatin-modifying complex. Nat Cell Biol 2004, 6(2): I62-167.

50. Srinivasan S, Armstrong JA, Deuring R, Dahlsveen IK, McNeill H, Tamkun JW: The Drosophila trithorax group protein Kismet facilitates an early step in transcriptional elongation by RNA Polymerase II. Development 2005, I32(7): | 623-I635.

51. The Flybase consortium: The FlyBase database of the Drosophila genome projects and community literature. Nucleic Acids Res 2003, 3 I (I): I 72-I75.

52. Cavalli G, Orlando V, Paro R: Mapping DNA target sites of chromatin-associated proteins by formaldehyde cross-linking in Drosophila embryos. In Chromosome Structural Analysis: A Practical Approach Edited by: Bickmore WA. Oxford University Press UK; 1999:20-37.
Publish with Biomed Central and every scientist can read your work free of charge

"BioMed Central will be the most significant development for disseminating the results of biomedical research in our lifetime. "

Sir Paul Nurse, Cancer Research UK

Your research papers will be:

- available free of charge to the entire biomedical community

- peer reviewed and published immediately upon acceptance

- cited in PubMed and archived on PubMed Central

- yours - you keep the copyright
BiolMedcentral 